\title{
A proposta de universalismo das Nações Unidas e a efetivação de Direitos Humanos no cenário mundial transnacional
}

The United Nations proposal for universalism and the effectiveness of human rights in the transnational world scenario

Regiane Nistler

Universidade Estácio de Sá (UNESA), Rio de Janeiro

regianenistler@outlook.com

Jéssica Cindy Kempfer (D)

Faculdade Meridional (IMED), Campus de Passo Fundo/RS

jessicakempfer@gmail.com

Caroline Bresolin Maia Cadore

Universidade de Coimbra

carolbresolinm@gmail.com 
0 estudo em tela tem como objetivo geral apontar o aparente fracasso do universalismo das Nações Unidas (ONU) no que tange a efetivação de direitos humanos e a ascensão de novos atores nessa missão. Diante disso, a pesquisa foi dividida em três seções que, inclusive, evidenciam os seus objetivos específicos: (1) tecer breves considerações sobre direitos humanos e o universalismo das Nações Unidas; (2) estudar a globalização e suas consequências, especialmente o surgimento do transnacionalismo e atores transnacionais como empresas e Organizações Não-Governamentais (ONG's); e (3) analisar a efetivação dos direitos humanos no cenário transnacional. A título de considerações finais o trabalho dá ênfase especialmente pelos casos estudados, quanto a atuação destacada de atores transnacionais no que tange a efetivação de direitos humanos. 0 método utilizado foi o indutivo e a técnica de pesquisa escolhida foi a bibliográfica.

Palavras-chave: Direitos Humanos; Universalismo; ONU; Globalização; Transnacionalismo.

\section{Abstract}

The study on screen has the general objective of pointing out the apparent failure of the United Nations (UN) universalism in terms of the realization of human rights and the rise of new actors in this mission. In view of this, the research was divided into three sections that even highlight its specific objectives: (1) to make brief considerations about human rights and the universalism of the United Nations; (2) to study globalization and its consequences, especially the emergence of transnationalism and transnational actors such as companies and Non-Governmental Organizations (NGOs); and (3) to analyze the realization of human rights in the transnational scenario. As final considerations, the work emphasizes, especially for the cases studied, regarding the outstanding performance of transnational actors with regard to the realization of human rights. The method used was inductive and the chosen research technique was bibliographic.

Keywords: Human rights; Universalism; UN; Globalization; Transnationalism. 
0 trabalho em apreço tem como objetivo geral apontar o aparente fracasso do universalismo das Nações Unidas (ONU), também chamado de universalismo onusiano, no que tange a efetivação de direitos humanos. Para tanto, estabelece a seguinte problemática: o trôpego universalismo do sistema internacional de proteção dos direitos humanos tem sucesso na efetivação dos respectivos direitos no cenário transnacional?

Enquanto hipótese estabelece 0 seguinte: supõe-se que o sistema tradicional de proteção de direitos humanos, mesmo com tanta catalogação de direitos, campanhas na busca de proteção, adesão de Estados, entre outros feitos, mostra-se no mínimo insuficiente para efetivar direitos humanos, especialmente ao ser comparado com a atuação destacada dos atores que surgem no atual cenário transnacional, notadamente empresas transnacionais e Organizações NãoGovernamentais (ONG's), normalmente mantidas com recursos privados das primeiras.

Diante disso, a pesquisa foi dividida em três seções que, inclusive, evidenciam os seus objetivos específicos, sendo a primeira para estudar os direitos humanos, com uma tentativa de conceito e demonstração de sua relevância, bem como fazer apontamentos acerca do universalismo das Nações Unidas.

A segunda seção foi criada para abordar a globalização e seu fenômeno consequentemente, qual seja, 0 transnacionalismo. A partir dele tratar dos atores transnacionais, especialmente empresas e Organizações Não-Governamentais (ONG's), sendo estas últimas na maioria das vezes mantidas com recursos privados das primeiras.

$E$, por fim, estendendo a narrativa iniciada na seção dois, buscarei na terceira demonstrar através de casos concreto, a importância e exitosa atuação das empresas transnacionais no que tange a efetivação de direitos humanos, especialmente pelas suas atitudes in loco, pela desburocratização do setor privado e, claro, pelos recursos vultosos que este possui.

A título de adendo importante consignar que 60 este trabalho não ignora casos escancarados de violação aos direitos humanos por atores transnacionais, especialmente grandes empresas, mas este ensaio propõe uma visão positiva, com demonstração através de casos concretos, quanto a importância da atuação e investimento das mesmas em matéria de efetivação de direitos humanos.

\section{Direitos humanos e o universalismo das Nações Unidas}

Os direitos humanos são, na verdade, difíceis de serem conceituados e isso acontece, narra Lynn Hunt (2009, p. 22-23), porque sua definição é a sua própria existência, dependendo tanto da razão, quanto e muito da emoção. Isso porque sabe-se que é um direito humano que está em questão em determinado cenário quando há sentimento de horror pela sua violação.

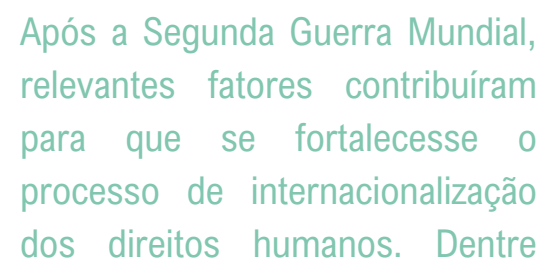


eles, um dos mais importantes fol a maciça expansão de organizaçoes internacionais com propósitos de cooperação internacional (PIOVESAN, 2015, p. 204).

0 nascimento da $\mathrm{ONU}$, juntamente com suas agências especializadas (programas e fundos), como organizações internacionais, marca 0 surgimento de uma nova ordem internacional, que instaura um novo modelo de conduta nas relações internacionais, com preocupações, num plano teórico, que incluem a manutenção da paz e segurança internacional, o desenvolvimento de relações internacionais amistosas entre os Estados, a adoção de um padrão internacional de saúde, a proteção ao meio ambiente, a criação de uma nova ordem econômica internacional e a proteção internacional dos Direitos Humanos (PIOVESAN, 2015, p. 204).

A Organização das Nações Unidas, criada pela Carta da ONU, datada em 26 de junho de 1945, contou inicialmente com cinquenta e um Estados, incluindo o Brasil (hoje conta com 193 países membros), sendo estabelecida sua sede em Nova York. Ela teve como fundamento a necessidade de preservar as futuras gerações do "flagelo da guerra", conforme se verifica logo no preâmbulo da Carta, devendo assim, estar envolvida em todas as grandes crises existentes no âmbito da sociedade internacional (GUERRA, 2016, p. 107).

Além disso, a Carta da organização das Nações Unidas estabelece como propósitos principais a manutenção da paz e a segurança internacional; fomentar as relações amistosas entre as nações baseadas no respeito e na igualdade de direitos e autodeterminação dos povos; cooperar na resolução de problemas internacionais de caráter econômico, cultural e humanitário; estimular o respeito dos direitos humanos e das liberdades fundamentais (GUERRA, 2016, p. 108).
Pois bem, acerca do universalismo onusiano, este estudo visa dar ênfase a algumas críticas existentes sobre o instituto, e embora isto seja feito ao longo de todo o texto, desenvolve esta seção para demonstrar por meio de aportes teóricos as razões que motivam as críticas ao sistema.

0 processo de internacionalização evidencia a formalização do universalismo dos direitos humanos e a tentativa de proteção global desses direitos, como é possível perceber no título, no preâmbulo e nos textos de vários dos documentos internacionais de proteção dos direitos humanos e da proposta dos sistemas regionais de proteção (europeu, americano e africano). Portanto, antes de adentrar às críticas propriamente ditas, algumas considerações acerca do instituto do universalismo se mostram necessárias para melhor compreensão do tema.

0 critério universalista contribui para o fato de serem os direitos humanos, nos dias atuais, uma mentira. Isso porque, para o autor, que faz afirmação extrema, embora os direitos humanos, no sistema universal sejam declarados em nome do homem universal, 0 sistema evidencia um processo de associação institucional pelos Estados e por consequência possível adesão pelos cidadãos que ostentam sua nacionalidade, 0 que demonstra um processo formal que não traz qualquer registro de concretização do suposto universalismo em razão desse expediente (DOUZINAS, 2009, p. 99).

0 ponto é que apesar dos processos de revolução terem representado a passagem dos direitos naturais para humanos, dando início ao período histórico da Modernidade, assim como o processo de internacionalização dos direitos humanos ter representado um marco no que tange a promoção da paz mundial, por ocasião do pós-guerra e até mesmo a positivação de tantos direitos dessa natureza, fixou claramente, em especial este último, a ideia 
fortalecida do nacionalismo e por conseguinte a cidadania dos indivíduos, que neste contexto representa uma nítida forma de exclusão.

0 autor Sidney Guerra (2016, p. 186) destaca que ao partir de um ponto de vista particular, que envolve a comunidade, a doutrina concebe uma série de críticas à concepção universalista dos direitos humanos, por exemplo, que a noção de direitos humanos vai de encontro à noção de obrigações proclamados por muitos povos; o conceito de direitos humanos leva em consideração uma visão antropocêntrica do mundo, que não é compartilhada por todas as culturas; o cunho ocidental da visão dos direitos humanos, que pretende ser geral e imperialista; a falta de adesão formal por parte de muitos Estados aos tratados de direitos humanos ou a falta de políticas com efetivo comprometimento com tais direitos, são indicativos da impossibilidade do universalismo.

$\mathrm{Na}$ doutrina de Boaventura (2003) o universalismo onusiano é criticado por representar um localismo globalizado, que demonstra um movimento no qual um evento local é globalizado com êxito. Para o autor, o universalismo declarado é de valor exclusivamente ocidental e representa um choque de civilizações, pois é imposto de cima para baixo.

Além disso, ensina Herrera Flores (2009, p. 86), que não se deve entender os direitos humanos ou qualquer outra temática, enquanto objeto de investigação, de uma forma isolada e por um critério absoluto, mas sempre considerando o restante dos pressupostos $\mathrm{e}$ fenômenos que se verificam na sociedade.

Inclusive, por esse e outros motivos acima expostos, esta pesquisa critica o pseudo sistema universal e faz adesão a uma concepção integral de direitos humanos. 0 que se defende é uma abordagem que supere 0 excesso de formalidade e ao mesmo tempo o formato simplista do registro de direitos humanos intitulados e classificados.

Nesse sentido, novamente é a doutrina de Herrera Flores (2009, p. 84-85), que ao tratar de uma concepção integral de direitos humanos, aduz que respectivos direitos devem observar, considerar e concretizar o que ele chama de (a) integridade corporal; (b) satisfação das necessidades e (c) reconhecimento à diferença.

Ou seja, a condição humana e tão somente ela implica de plano na titularidade de direitos humanos, sendo que esses direitos devem ser concretos a ponto de atender as necessidades específicas dos indivíduos que ostentam culturas diversas e diferenças, embora a mesma condição de humanidade. Não se fala aqui em mais e mais direitos, ao revés, são os mesmos direitos acima mencionados, mas para aqueles que possuem a essência humana.

Por oportuno, é válido dissertar, utilizando os ensinamentos de Staffen (2016, p. 178-208) 62 que não se está aqui, a defender a tese de afastamento do ente estatal e das instituições clássicas de Direito Internacional no que tange as suas responsabilidades para com os direitos humanos.

0 que se defende é uma postura não ingênua que não se restringe na ideia de que os Estados são providos de capacidade exclusiva e vontade quando o assunto é efetivação de direitos humanos, seja pela herança histórica, seja pela fragilidade da sua figura e da sua atuação diante das mudanças trazidas pela globalização (STAFFEN, 2016, p. 178-208).

Em síntese, pretende-se desenhar "um novo nível de sustentação para o sistema de freios e contrapesos, situado nos espaços globais, envolvendo os agentes globais com 0 desiderato de satisfação dos direitos humanos em outros níveis". (STAFFEN, 2016, p. 178208). 
Assim, realizadas as considerações acerca dos direitos humanos que se entendem necessárias para a fundamentação desse estudo, a seção a seguir trata do conteúdo introduzido pelos parágrafos anteriores, qual seja, as transformações suportadas pelo mundo em razão do fenômeno da globalização e do transnacionalismo, bem como o impacto disso na temática direitos humanos num plano de efetivação.

\section{Globalização e uma de suas principais consequências: o Transnacionalismo}

Globalização continua sendo o melhor termo para representar as profundas mudanças ocorridas em nível mundial e global, acirradas, principalmente, após o fim da disputa ideológica entre capitalismo e socialismo, simbolizada pela queda do muro de Berlin que precipitou a globalização econômica e a hegemonia capitalista, bem como a grave crise financeira global que teve de ser enfrentada como seu subproduto (CRUZ, 2011, p. 105).

Nesse caminho Held e McGrew (2002, p. 12) explicam o seguinte:

\section{[...] o conceito de Globalização denota muito mais do que a ampliação de relações e atividades sociais atravessando regiões e fronteiras. É que ele sugere uma magnitude ou intensidade crescente de fluxos globais, de tal monta que os Estados e sociedades ficam cada vez mais enredados em sistemas mundiais e redes de interação. Em consequência disso, ocorrências e fenômenos distantes podem passar a ter sérios impactos internos, enquanto os acontecimentos locais podem gerar repercussões globais de peso. Em outras palavras, a Globalização representa uma mudança significativa no alcance espacial da ação e da organização}

sociais, que passa para uma escala inter-regional ou intercontinental.

Enquanto isso, para Cassese (2002, p. 25), a Globalização consiste em desenvolvimento de redes de produção internacionais, dispersão de unidades produtivas em diferentes países, fragmentação e flexibilidade do processo de produção, interpenetração de mercados, instantaneidade dos fluxos financeiros e informativos, modificação dos tipos de riqueza e trabalho e padronização universal dos meios de negociação.

Em que pese seja um fenômeno não concluído, como leciona Habermas (2001, p. 84), a globalização tem alterado o modo de vida das pessoas, intensificando as relações de troca, de comunicação, e de trânsito, para além das fronteiras nacionais, a expansão massificada das telecomunicações, turismo, cultura, com reflexos no ecossistema e nas relações das organizações governamentais e não governamentais, caracterizada por profunda concepção hegemônica do capital, de ideologia neoliberal.

Ainda, para Clark, assim como para Paul Hirst (1996), para Andrew Hurrell (1995) e Saskia Sassen (1998), os Estados e os governos - de modo todo particular os governos das grandes potências - não são testemunhas passivas da globalização: eles são, pelo contrário, quem a promove e a difunde, recorrendo quando é 
necessário, também ao uso da força. Contra a tese sustentada por Ulrich Beck, da irreversível passagem à segunda modernidade - em âmbito civil, econômico, técnico-comunicativo, ecológico - a globalização é pensada por esses autores como um processo histórico, descontínuo e conflitual, a par de qualquer outro processo histórico (ZOLO, 2010, p. 1718).

E um desses acontecimentos é o transnacionalismo, que, além de nascer do cenário contemporâneo, segundo Stelzer (2011, p. 21), insere-se no contexto da globalização e liga-se fortemente à concepção do transpasse estatal, enquanto globalização remete à ideia de conjunto, de globo, enfim, o mundo sintetizado como único; transnacionalização está atada à referência do Estado permeável, mas tem na figura estatal a referência do ente em declínio.

É o "mundo novo", que precisa ser explorado no espaço limítrofe entre o Estado e as sociedades nacionais (Beck, 1999, p. 190), sendo que são desafios de um mundo globalizado e nos ensinamentos de Oliviero e Cruz (2016, p. 2012):

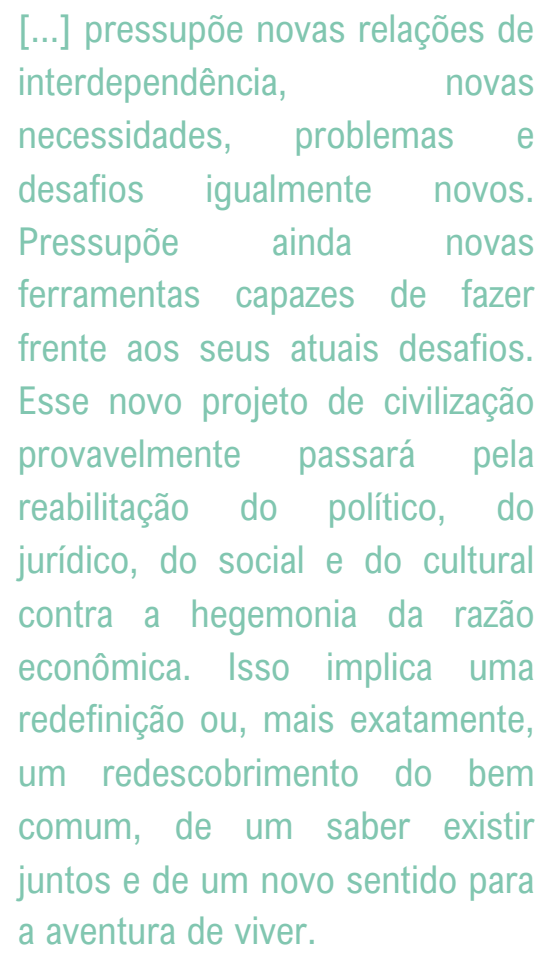

Assim, a Globalização se trata de um fenômeno que nas lições de Habermas (2001, p. 84) "é um processo e não um estado final" está reestruturando o modo como os indivíduos vivem e, de maneira bastante indelével, está causando impacto nas tradicionais estruturas que até então estavam postas na sociedade. Consequentemente, os reflexos de toda essa miscelânea acabam servindo como base de sustentação para o surgimento de outros fenômenos, influenciando a vida cotidiana tanto quanto eventos que ocorrem numa escala em nível global.

E um desses acontecimentos é 0 Transnacionalismo, que, além de nascer do contexto contemporâneo, segundo Stelzer, insere-se no contexto da Globalização e liga-se fortemente à concepção do transpasse estatal, enquanto Globalização remete à ideia de conjunto, de globo, enfim, o mundo sintetizado como único; transnacionalização está atada à referência do Estado permeável, mas tem na figura estatal a referência do ente em declínio 64 (STELZER, 2011, p. 21).

\section{[...] representa o novo contexto mundial, surgido principalmente a partir da intensificação das operações de natureza econômico-comercial no período do pós-guerra, caracterizado - especialmente _ - $\quad$ pela desterritorialização, expansão capitalista, enfraquecimento da soberania e emergência de ordenamento jurídico gerado à margem do monopólio estatal.}

Ou seja, é desse "mundo novo" que nasce a ideia de Transnacionalismo, que tem sido objeto de inúmeros escritos e debates jurídicos, em especial, por ser um fenômeno em construção, 0 que será tratado minuciosamente a seguir. 
0 prefixo "trans" trata da capacidade não apenas da justaposição de instituições ou da superação/transposição de espaços territoriais, mas a possibilidade da emergência de novas instituições multidimensionais, objetivando a produção de respostas mais satisfatórias aos fenômenos globais contemporâneos (CRUZ; BODNAR, 2011, p. 55-71). Dessa forma, a expressão latina "trans" significaria algo que vai "além de" ou "para além de", a fim de evidenciar a superação de um locus determinado, que indicaria que são perpassadas diversas categorias unitárias, num constante fenômeno de desconstrução e construção de significados.

Ainda, Philip Jessup (1965, p. 11), há muito, mais precisamente em 1956, abordou o tema, ao trazer a expressão "Direito Transnacional" referindo-se ao emaranhado de regras de cunho jurídico aplicáveis às relações sociais que comportam um elemento de "estraneidade", como será exposto a seguir em

tópico específico criado para o Direito Transnacional (JESSUP, 1965).

Outrossim, adverte Philip Jessup (1965, p. 11), que o termo "internacional" para se referir aos Estados e suas relações é bastante enganador, pois, não obstante passar a ideia de entrelaçamento entre Estados sugere, por outro lado, a preocupação apenas com as relações que se dão entre uma nação [ou Estado] com outras nações [ou Estados]' sendo que se tem necessidade de uma reflexão para além das fronteiras, logo, uma dimensão transnacional.

0 território transnacional não é nem um nem outro e é um e outro, posto que se situa na fronteira transpassada, na borda permeável do Estado. Com isso, por ser fugidia, borda também não é, pois, fronteira delimita e a permeabilidade traz consigo apenas 0 imaginário, o limite virtual. Aquilo que é transpassável não contém, está lá e cá (STELZER, 2011, p. 25-27).
Logo, a característica da desterritorialidade sinaliza que o espaço transnacional que ela cria não se confunde com 0 território exclusivamente estatal, também não pode ser confundido com o espaço que liga dois ou mais espaços estatais (como nas relações internacionais e supranacionais), "não é nem um nem outro e é um e outro, posto que se situa na fronteira transpassada, na borda permeável do Estado", destaca Stelzer (2011, p. 25).

Outrossim, é possível dizer que desterritorialização representa um nível superior de integração onde as fronteiras desaparecem. Momento em que se supera o conceito fronteiriço de Estado-nação. Assim, ao tratar de relações transnacionais, se está a relacionar com o que é do Estado, com o que se relaciona entre os Estados e o que está além do Estado. Desta forma, questões ou problemáticas que antes eram tratadas em nível singular (estatal), passam a ser tratadas de forma plural (DEMARCHI, 2012, p. 114115).

Adiante, outra característica relevante é o enfraquecimento do Estado soberano, motivo pelo qual Cruz (2011, p. 97) afirma que a soberania, um dos paradigmas do Estado Constitucional Moderno que convertia o poder estatal num poder supremo, exclusivo, irresistível e substantivo, único senhor criador de normas e detentor do monopólio do poder de coerção física legítima dentro de seu território, ao tempo que único interlocutor autorizado a falar com o exterior, está se desmanchando, o que faz afundar os alicerces sobre os quais se sustentava a teoria clássica do Estado Constitucional Moderno.

0 autor Manuel Castells (1.999, p. 164) define o surgimento de um novo tipo de Estado, que não elimina o estado nacional, mas o redefine, sendo que o Estado, por ele denominado, é chamado de "Estado-rede" que se caracteriza por compartilhar a autoridade [ou seja, a 
capacidade institucional de impor uma decisão] através de uma série de instituições. Uma rede, por definição, não tem centro e sim nós, de diferentes dimensões e com relações intermodais que são frequentemente assimétricas.

Enfim, todos os nós são necessários para a existência da rede. Assim, o Estado-nação se articula cotidianamente na tomada de decisões com instituições supranacionais de distintos tipos e em distintos âmbitos. Nesta rede funcional instituições regionais e locais inclusive que contam com a participação de organizações não governamentais $(1.999, \mathrm{p}$. 164).

Além disso, a ultravalorização do capitalismo ou do dinheiro também se mostra como uma das características do transnacionalismo, que para Cazzaro utilizando-se os ensinamentos de Stelzer (2011, p. 28) foi a queda do bloco soviético quem fomentou as condições ideais para que o espírito capitalista assumisse, de uma vez por todas, as rédeas do passo mundial. A partir de então, a busca do lucro tornou-se o espírito vetor e definiu as interações tanto no plano interno quanto no plano externo e o mundo tomou visos globalizantes em proporções até então nunca vistas (CAZZARO, 2015, p. 171-172).

Isso porque no cenário transnacional, decorrente da globalização e repleto de relações comerciais na busca incessante por lucro, o mercado visa se utilizar de rotas e ferramentas que não sejam barradas nas fronteiras tradicionais da normatização interna dos países (STELZER, p. 31).

Outrossim no transnacionalismo estão inseridas demandas que são de natureza individual, coletiva e até mesmo difusa simultaneamente, inclusive, intituladas de transindividuais. São, por conseguinte, transfronteiriças, uma vez que a proteção delas não acontece no interior das fronteiras nacionais de cada Estado. Logo, não interessam apenas a um ou poucos, mas a diversos, a uma coletividade que se encontra entrelaçada nesse novo cenário mundial (CAZZARO, 2015, p. 177).

Neste cenário surge o que se intitula por atores transnacionais, sendo imprescindivel destacar que para que surjam esses atores é necessário que o sistema ostente diversos centros de autoridade política, à medida que se os Estados fossem integralmente autárquicos, ou seja, obtivessem total centralidade política e se as demandas internacionais fossem geridas apenas por funcionários estatais, não haveria atores transnacionais (KRASNER, 1995, p. 258).

Ator transnacional significa quaisquer expedientes ou relações na esfera transnacional, sendo que nos dias de hoje 0 mundo é palco de vários atores diferentes, que são simultaneamente desiguais $\mathrm{e}$ interdependentes. 0 velho ator era, principalmente, o Estado-Nação, que continua existindo, como bem frisado nesta pesquisa, mas com novo papel (SANTOS, 2015, p. 173).

A expressão "atores transnacionais", nessa pesquisa, é utilizada para fazer referência a instituições, especialmente empresas transnacionais e organizações nãogovernamentais (ONG's), que em certa medida têm assumido posturas que até então eram vistas e esperadas do Estado, além da eficiência demonstrada com respectivas competências, ainda que assumidas num plano informal.

Nos ensinamentos de lanni (1995, p. 135), as empresas transnacionais, sem prejuízo de outras corporações e conglomerados intitulados como multinacionais, mundiais, globais ou planetários, são responsáveis pela formação, funcionamento e transformação do que se poderia chamar de shopping center global, espalhando-se por países e continentes, 
sendo que isso pode ser analisado como um enorme caleidoscópico arsenal de mercadorias, originárias de uma fábrica múltipla e monumental, organizada por alguns e dispersa por todo o mundo.

As Organizações Não Governamentais (ONG's) talvez sejam as entidades que melhor indicam o "caos sistêmico" ou a desordem sócio espacial resultado da tensão de territorialidade que se verifica, até porque em torno delas é que 0 fenômeno rede, fundamental no desordenamento do espaço contemporâneo, conquista sua maior legitimidade. Afinal, as ONG's não só contribuem para debilitar 0 Estado-nação na sua concepção "Westphaliana", como, ao mesmo tempo, colocam novos desafios aos movimentos sociais (COSTA, PORTO-GONÇALVES, 2006, p. 69).

Diante do exposto, e em atenção ao objeto desta pesquisa, a seção seguinte este estudo se debruça em casos reais de atuação de empresas transnacionais e organizações nãogovernamentais (ONG's), que demonstram a efetivação de direitos humanos na seara global. Isso porque, referidos atores, por expedientes próprios e informais agem de forma competente na concretização de direitos elementares e questionam as bases de clássicas do sistema internacional de direitos humanos e seu discurso universalista.

\section{A efetivação dos direitos humanos no cenário transnacional}

0 indiano Parag Khanna (2011, p. 123) é incisivo ao afirmar que "problemas transnacionais precisam de soluções transnacionais, não de resoluções da ONU". Isso porque, critica o autor, a heterogênea mistura de comitês e agências da ONU que lidam, principalmente, mas não somente, com ameaças transnacionais que se referem ao terrorismo, ao crime organizado, a proliferação de armas nucleares e ao tráfico de drogas, por exemplo, atuam como se essas demandas compusessem um conjunto único de soluções e não se trata disso (KHANNA, 2011, p. 123124).

Contudo, embora este estudo faça adesão a estes argumentos, assim como à declaração de Karen Tse, fundadora da organização sem fins lucrativos International Bridges of Justice (IBJ), de que "ninguém protege direitos humanos com relatórios. Os últimos sessenta anos foram consumidos com declarações; é hora de agir" (KHANNA, 2011, p. 141), não desconsidera a importância da construção do sistema internacional de proteção dos direitos humanos, tanto pelas suas instituições quanto pelos documentos internacionais e por isso os mencionou na seção anterior.

Todavia, os sinais de colapso na efetivação de direitos humanos pelos expedientes formais clássicos, em especial o sistema internacional, têm evidenciado um novo cenário, que tem como pano de fundo as consequências da globalização acima referidas.

0 que se percebe são atores transnacionais fazendo o trabalho de efetivar direitos humanos com muita competência e destaque, mesmo utilizando seus meios informais de atuação, e, por vezes, com algum interesse econômico por trás disso, uma vez que consideram o óbvio: uma sociedade que possui direitos elementares garantidos, é menos desigual, produz mais e consome muito mais. 
Pois bem, em atenção aos casos reais, convém lembrar que em 2009, quando a política dos EUA finalmente mudou, fazendo com que grupos de ajuda comprassem de vendedores próximos, a International Relief and Development (IRD) celebrou parceria com empresas do ramo alimentício da Indonésia para aumentar sua produção de arroz, macarrão oriental com ovos e biscoitos de trigo, além de melhorar sua logística para levar os produtos por todo território nacional, programa reproduzido no Camboja, ao Niger e no Sri Lanka (KHANNA, 2011, p. 184).

A IRD chega a construir pequenas vias secundárias no Iraque e no Afeganistão para auxiliar o retorno dos negócios agrícolas. Com o apoio do Departamento para o Desenvolvimento Internacional do Reino Unido, no intuito de subsidiar sacos de fertilizante por um terço do valor de mercado, o Malawi passou das baixas colheitas e da fome de 2005 para a produção de mais de 3 bilhões de toneladas de milho no ano de 2007, comercializando o restante para o Programa Alimentar Mundial (KHANNA, 2011, p. 184).

A Fundação Gates não só pagou a bemsucedida Aliança Global para Vacinas e Imunizações dez anos atrás, como há pouco tempo, bancou o Institute for One World Health, a primeira companhia farmacêutica sem fins rentáveis, dedicado a saúde e a pesquisa de vacinas para os pobres, gastando mais nos últimos dez anos com pesquisas sobre doenças negligenciadas do que todos os governos do mundo juntos. Ainda, a Fundação criou o Global Health Program, que nasceu com o objetivo de combater a poliomielite, fornecer suporte à pesquisa de HIVIAIDS e promover $\mathrm{e}$ distribuir vacinas para crianças (KOTLER, LEE, 2010, p. 257-258).

A Pratham, uma ONG indiana, foi a procura do que motiva o fato de a maioria das crianças classificadas como alfabetizadas não saberem ler o próprio idioma. Hoje, a Pratham é dona das campanhas educacionais mais conhecidas do país, e intitula seu programa em seu site oficial como "A jornada que começou a eliminar o ciclo da pobreza erradicando o analfabetismo da Índia". (KHANNA, 2011, p. 189)

Compreendendo a raiz do problema e começando

Pratham percebeu que o primeiro passo para alcançar a educação primária universal é alcançar a educação pré-escolar universal, e trabalhou para este objetivo através do Balwadi (pré-escolar) do programa. Começou por fornecer educação pré-escolar para crianças nas favelas de Mumbai, como dito. Logo, o Pratham Balwadis foi multiplicado e este modelo bem-sucedido restou adotado em outros estados em toda a nação. A instituição é autora do "Aprenda a ler" - o programa que demonstrou que a aprendizagem pode ser melhorada num curto intervalo de tempo e a um baixo custo. Em 2008, Pratham associouse com o Sr. Sudesh Arora para a formação específica da indústria que deu origem ao Pratham Arora Centro de Educação (PACE). A PACE introduziu cursos específicos para a indústria de serviços de hospitalidade, construção, automoção e assistência ao leito. 0 programa Educação para a Educação (EFE) foi desenvolvido para voluntários para ensinar na campanha Read India, com o objetivo de fortalecer a capacidade de voluntariado. (KHANNA, 2011, p. 189)

Iniciando as conclusões o ponto nevrálgico é a importância de falar da globalização e suas consequências em relação a essas questões, pois como destaca Arnaud (2007, p. 214), deve haver uma implementação dos direitos humanos "tanto por baixo quanto por cima, do nível local ao nível global".

0 italiano Stefano Rodotà (2015, p. 06-07) destaca que o homem abstrato se torna um homem concreto, não mais em um Estado de Direito, mas sim em espaços de direitos, nos quais a soberania inerente aos Estados passa a 
ser ostentada pelos próprios homens, o que precisa ser considerado quando a pauta é efetivação dos direitos humanos. Isso ocorre, narra o autor, porque as bases legitimadoras da participação, da informação e da transparência foram alteradas. Inclusive, basta verificar os últimos acontecimentos pelo mundo que evidenciam práticas de direitos, bem como requerimentos de efetivação de direitos diretamente pelos homens, em utilização e sendo atendidos por outros expedientes, que não se tratam dos sistemas nacionais ou internacionais clássicos.

Ainda, Rodotà (2015, p. 06-07) destaca que tudo se expande no global e encolhe no local, motivo pelo qual é necessário encontrar meios de efetivar os direitos humanos através do que ele intitula de "democracia integral", pois sem a inserção dos direitos humanos na pauta da nova ordem global, a temática além de ineficaz servirá apenas para beneficiar alguns indivíduos. Logo, é possível concluir das lições do autor que a dimensão do ser humano e sua dignidade precisam estar no centro das atenções, onde a igualdade encontre a liberdade, o que forma uma "guarnição em face do totalitarismo", como ele próprio afirma.

Não se trata de chamar à responsabilidade alguns países, mas a reivindicação de um outro modo de entender os direitos humanos, os quais seguem uma nova aventura no mundo.
Uma globalização através dos direitos, não através dos mercados. "Outro universalismo é possível?" Questiona o autor italiano. Uma nova e difícil narrativa para os direitos é vislumbrada e 0 que se quer enfatizar é a imprescindibilidade de uma revolução pela igualdade, pela dignidade, cujo centro é a autodeterminação do indivíduo, construção da identidade individual e de responsabilidade pública. As línguas devem encontrar a chave das palavras de liberdade e de respeito, sem imposições (RODOTÁ, 2015, p. 15).

0 que se defende é uma tutela sem fronteiras para os direitos humanos, pois se percebe uma nova dimensão global, mas a velha tentativa de efetivar direitos. Isto quer dizer que as superadas formas de pensar a fronteira a partir do território e da soberania de um Estado já não são mais suficientes para oferecer proteção aos direitos (RODOTÁ, 2015, p. 18).

Portanto, pensar na efetivação dos direitos humanos no cenário transnacional, decorrente da nova ordem global, significa dizer que o ser humano não deve ser detentor de direitos humanos pelo território que se encontra, menos ainda pela nacionalidade que ostenta, requisitos que 0 universalismo onusiano destaca no plano prático, como visto, mas pela condição única e especial de ser humano que ele possui.

\section{Considerações Finais}

0 artigo apresentado teve como objetivo estudar o universalismo onusiano em análise de crítica e demonstrar o seu colapso no que tange a efetivação de direitos humanos na nova ordem transnacional decorrente da globalização.

Foi possível verificar que os direitos humanos são difíceis de serem conceituados, em especial por representarem uma temática que muda de acordo com o percurso histórico. No entanto, sabe-se que é um direito humano que está em questão quando há sentimento de horror e irresignação com a sua afronta.

0 estudo oportunizou analisar, ainda que brevemente, em razão da limitação física, os direitos humanos no plano internacional, em 
especial com a criação da Organização das Nações Unidas (ONU) e os documentos de proteção, que representam, no momento pósguerra um avanço importante para a sociedade global acerca da temática.

Todavia, o que se pode responder nesse aspecto e se mostra demasiadamente importante no presente estudo ensaio, é que há necessidade de desapego das formalidades exacerbadas quanto ao assunto direitos humanos, especialmente no que tange a sua efetivação, pois a inovação não está na formalização do direito, sem prejuízo da importância desse expediente, mas na sua concretização.

Aliás, o referido sistema, que se apresenta como universal ou como sistema pseudo global de direitos humanos, evidencia muito mais uma busca incansável por documentar direitos humanos no plano internacional, incentivando seu reconhecimento nas constituições internas e uma tentativa frustrada de efetivação, do que um canal realmente universal e promissor para o respeito e a concretude dos direitos humanos.

Nesse cenário, foi possível concluir pela imprescindibilidade de substituição do aparente ou nunca existente critério universalista dos direitos humanos apresentado pelo sistema internacional, pois o mesmo existe apenas num plano teórico e não serve para efetivar direitos humanos, pelo contrário, pode significar aspecto de desigualdade entre os países se considerar membros e não-membros.

E mais do que isso. 0 sistema internacional dos direitos humanos e seu critério universalista representam claro divórcio com as bases dos direitos humanos, amparadas especialmente pelo humanismo na sua concepção renascentista, que posiciona o ser humano no centro das atenções e não atribui a ele valor e dignidade pelo território onde se encontra, menos ainda pela nacionalidade que the foi atribuída, mas apenas por ser humano. 

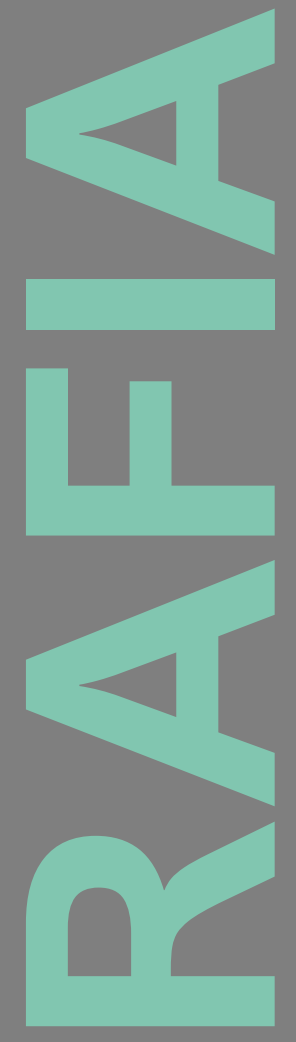

71
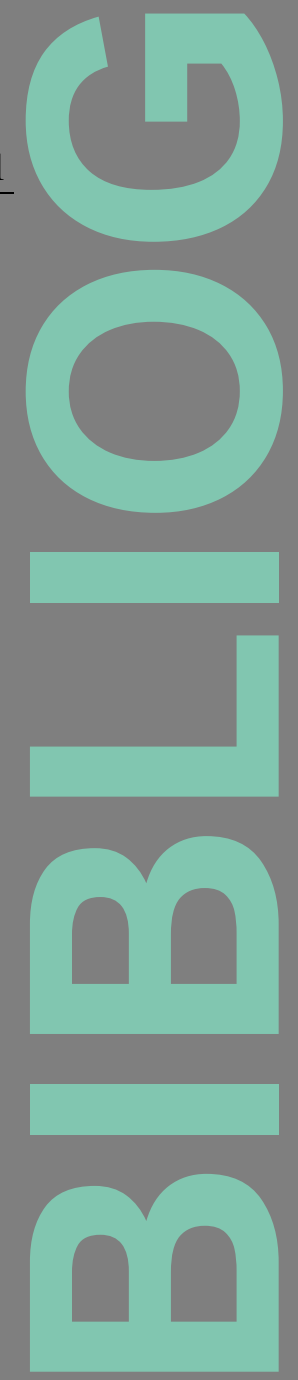

Arnaud, A. J. (2007). Governar sem fronteiras: entre globalização e pósglobalização. Rio de Janeiro: Lúmen Juris.

BECK, Ulrich. 0 que é globalização? Equívocos do globalismo. Respostas à globalização. São Paulo: Paz e Terra, 1999. Título original: Was ist glogalisierung? :Irrtümer des globalismus: Antworten auf globalisierung.

CASSESE, Sabino. A crise do Estado. Tradução Ilse Paschoal Moreira e Fernanda Landucci Ortale. São Paulo: Saberes, 2002.

CASTELLS, Manuel. Para o Estado-rede: globalização econômica e instituições políticas na era da informação. In: PEREIRA, Luiz Carlos Bresser; WILHEIM, Jorge; SOLA, Lourdes (Org). Sociedade e Estado em transformação. São Paulo: Editora Unesp, 1999.

Cazzaro, K. (2015). Arbitragem transnacional: limites e possibilidades. 2015. 440 f. Tese (Doutorado em Ciência Jurídica) - Centro de Ciências Sociais e Jurídicas, Universidade do Vale do Itajaí, Itajaí.

Costa, R. H. \& Porto-Gonçalves, C. W. (2006). A nova desordem mundial. São Paulo: Editora UNESP.

Cruz. P. M. (2011). Da soberania à transnacionalidade: democracia, direito, e Estado no século XXI. $1^{a}$ ed. Itajaí. Editora da UNIVALI.

Demarchi, C. (2012). Direito e Educação: a regulação da educação superior no contexto transnacional. 2012. 302 f. Tese (Doutorado em Ciência Jurídica) - Centro de Ciências Sociais e Jurídicas, Universidade do Vale do Itajaí, Itajaí.

Douzinas, C. (2009). 0 fim dos direitos humanos. Tradução: Luzia Araújo. São Leopoldo (RS): Unisinos.

Guerra, S. (2016). Direitos humanos: curso elementar. 4. ed. São Paulo: Saraiva.

Habermas, J. (2001). A constelação pós-nacional: ensaios políticos. São Paulo: Littera Mundi, 2001. Tradução de Márcio Seligmann-Silva. Título original: Die postnationale konstellation: politische essays.

Hegel, G. W. F. (1995). Enciclopédia das ciências filosóficas em compêndio: a ciência da lógica. Tradução: Paulo Meneses. São Paulo: Loyola.

HELD, David; MCGREW, Anthony. Governing Globalization: Power, Authority and Global Governance. Tradução nossa. Cambridge: Polity, 2002.

Herrera Flores, J. (2009). A reinvenção dos direitos humanos. Florianópolis: Fundação Boiteux.

Hunt, L. (2009). A invenção dos direitos humanos: uma história. Tradução de Rosaura Eichenberg. São Paulo: Companhia das Letras.

lanni, O. (1995). A sociedade global. 3. ed. Rio de Janeiro: Civilização Brasileira.

JESSUP, Philip C. Direito transnacional. Tradução de Carlos Ramires Pinheiro da Silva. Lisboa: Fundo de cultura, 1965. Título original: Transnational Law. 
Khanna, P. (2011). Como governar o mundo: um roteiro para o próximo renascimento. Tradução de Berilo Vargas. Rio de Janeiro: Intrínseca.

Kotler, P. \& LEE, N. R. (2010). Marketing contra a pobreza: as ferramentas da mudança social para formuladores de políticas, empreendedores, ONGS, empresas e governos. Tradução: Sônia Augusto. Porto Alegre: Bookman.

Krasner, S. D. (1995). Power politics, institutions, and transnational relations. In: Risse-Kappen, T. Bringing transnational relations back in: non-state actors, dmestic structures and international institutions. Tradução nossa. Cambridge University Press. p. 258.

OLIVIERO, Maurizio; CRUZ, Paulo Márcio. Reflexões sobre o direito transnacional. Novos Estudos Jurídicos. Revista Eletrônica. vol. 17. n. 1. Itajaí, SC. jan-abr 2012. p. 18-28. Disponivel em: <http://siaiweb06.univali.br/seer/index.php/nej/article/view/3635/2178>. Acesso em 24 de jul. de 2020.

Piovesan. F. (2015). Direitos humanos e o direito constitucional internacional. 15. ed. São Paulo: Saraiva.

Prathan. Disponivel em: <http://www.pratham.org/about-us/history> Acesso em: 20 abr. 2017. Tradução nossa.

Rodotà, S. (2015). II diritto di avere diritti. Tradução nossa. Roma: Editori Laterza.

Santos, B. S. (2003). Para uma concepção multicultural dos Direitos Humanos. Disponível em: $<$ http://www.boaventuradesousasantos.pt/media/pdfs/Concepcao_multi c ultural_direitos_humanos_Contextolnternacional01.PDF>. 2003. Acesso em: 12 fev. 2017.

Santos, R. P. (2015). 0 princípio da dignidade da pessoa humana como regulador da economia do espaço transnacional: uma proposta de economia humanista. 2015. 568 p. Tese (Doutorado em Ciência Jurídica) - Centro de Educação de Ciências Sociais e Jurídicas CEJURPS, Universidade do Vale do Itajaí.

Staffen, M. R. (2016). Direito Global: Humanismo e Direitos Humanos. RVMD, Brasilia. 10(1). p. 178-208, Jan-jun.

Stelzer, J. (2011). 0 fenômeno da transnacionalização da dimensão jurídica. In Cruz, P. M. \& Stelzer, J. (orgs.). Direito e transnacionalidade. $1^{\circ}$ ed., reimp. Curitiba: Juruá.

Zolo, D. (2010). Globalização: um mapa dos problemas. Tradução Anderson Vichinkeski Teixeira: Florianópolis. Conceito Editorial. 